\title{
Septic Arthritis: A Need to Strengthen the Referral Chain in a Developing Economy
}

\author{
Ikpeme A. Ikpeme ${ }^{1}$, Ngim E. Ngim ${ }^{1}$, Anthonia A. Ikpeme ${ }^{2}$, Afiong O. Oku ${ }^{3}$ \\ ${ }^{1}$ Department of Surgery, University of Calabar Teaching Hospital, Calabar, Nigeria; ${ }^{2}$ Department of Radiology, University of Cala- \\ bar Teaching Hospital, Calabar, Nigeria; ${ }^{3}$ Department of Community Medicine, University of Calabar Teaching Hospital, Calabar, \\ Nigeria. \\ Email: iaikpeme@yahoo.com
}

Received February $26^{\text {th }}, 2013$; revised May $6^{\text {th }}, 2013$; accepted May $24^{\text {th }}, 2013$

Copyright (C) 2013 Ikpeme A. Ikpeme et al. This is an open access article distributed under the Creative Commons Attribution License, which permits unrestricted use, distribution, and reproduction in any medium, provided the original work is properly cited.

\begin{abstract}
Aim: This retrospective analysis documents the features and factors that potentially affect outcomes in septic arthritis in the Cross River Basin area of south-south Nigeria. Patients and Methods: A retrospective analysis of 43 patients who presented with septic arthritis in 45 joints between September 2007 and August 2010. All patients with pain, fever, joint swelling and non-weight bearing/refusal to move the limb and had a joint aspiration productive of a turbid and/or purulent aspirate were included in the analysis. Patients whose joint aspiration produced frank blood or a clear exudate were excluded. Results: There were 24 males and 19 females $(\mathrm{M}: \mathrm{F}=1.3: 1)$. Forty patients were children while three were adults. Thirty-three patients were urban dwellers, 8 were semi-urban dwellers and 2 were rural dwellers. Twenty-five children were first seen by a Paediatrician. Only 5 patients were first seen by an Orthopaedic surgeon. Definitive treatment was conservative in 28 children and arthrotomy/washout in 12 children and 3 adults. Staphylococcus aureus was the commonest isolated pathogen in both age groups. Conclusion: Injudicious interventions in musculoskeletal conditions consist not only of traditional bone setting and other unorthodox practices, but also sub-optimal orthodox medical practices. Healthcare outcomes in Africa are a function of the skewed distribution of the healthcare workforce and a weak referral chain. The near absence of follow-up culture underscores the need for education on injudicious antibiotic therapy to be directed at patients and physicians. Judicious interventions in musculoskeletal sepsis at first contact and a strengthening of the referral chain are important.
\end{abstract}

Keywords: Septic Arthritis; Health Seeking Contact; Definitive Treatment; South-South Nigeria

\section{Introduction}

Pyogenic joint infections are surgical emergencies [1]. Being a commoner in children, the risk of rapid joint destruction, irreversible impairment of joint function and fatality, especially in neonates, underscores the need for prompt diagnosis and appropriate treatment. Permanent skeletal deformity can be a sequel of septic arthritis and in developing countries, septic arthritis can be a disabling and life threatening disease [1]. As with other orthopaedic conditions, late presentation, injudicious intervention by traditional bone setters and illiteracy are well documented factors that influence treatment outcomes for orthopaedic ailments in the developing world [2,3]. In the developed world, favorable long term outcomes are not uncommon in septic arthritis [1].

Previous Nigerian studies have documented the aeti- ology, presentation and outcome of this disease [1,4-6]. Studies also identify the paucity of African data in this condition $[3,4,6]$. The large joints including the hip, knee and shoulder are the most commonly affected and the disease is commoner in males. Although Staphylococcus aureus is the commonest identified organism [1,4-6], coliforms follow closely in a Nigerian local study [4]. Joint trauma has been identified as a possible predisposeing factor $[1,3]$.

The burden of musculoskeletal sepsis in the developing world is enormous. The high incidence of complications because of late presentation and injudicious treatment of these conditions have also been documented [3]. These poor outcomes have been attributed to inadequate healthcare workforce distributions in Africa which ensure that these patients present first to general practitioners, paediatricians, herbalists, traditional bonesetters 
and surgeons without orthopaedic training [3]. Recent reports are now beginning to challenge the role of distance, poverty, lack of maternal education and care from traditional healers as the only significant underlying factors for late presentation and poor long term outcomes in Africa $[3,7,8]$. This is because in musculoskeletal septic conditions, inappropriate early antibiotic management or incorrect primary diagnoses are documented causes of late presentation with attendant poor long term outcomes in Africa [3]. The fact that orthopaedic surgeons or doctors with orthopaedic training are usually the last in the chain to see these patients may contribute significantly to late presentation and poor long term outcome.

Most episodes of acute septic arthritis result from haematogenous seeding of the vascular synovial membrane during a bacteraemia. Other routes of infection are direct inoculation and extension from a contiguous focus. Staphylococcus aureus is the most common cause of septic arthritis in Europe and all non-gonococcal septic arthritis in the United States [9]. Streptococcus species are the next most common isolates while Gram negative bacilli account for $10-20 \%$ cases. Patients with a history of intravenous drug abuse, immunocompromise or in the extremes of age have a higher prevalence of Gram negative infections. Polymicrobial infections occur in approximately $10 \%$ of patients with non gonococcal septic arthritis [9-11]. Historically, Haemophilus influenzae, Staphylococcus aureus and group A Streptococci were the commonest aetiologic organisms in children below the age of 2 years. However, the overall incidence of Haemophilus influenzae is decreasing because of the availability of Haemophilus influenzae type b (Hib) vaccine now being given to children [9].

The pathogenesis of septic arthritis is multifactorial and dependent on the interaction of the host immune response and bacterial adherence factors, toxins and immunoavoidance mechanisms. The synovial membrane is devoid of a limiting basement plate under the well vascularized synovium. This allows easy haemotogenous permeation of bacteria. Once bacteria are seeded in the joint space from any route of infection, low fluid shear properties encourage bacterial adherence and infection. In a joint that has undergone recent injury, the production of host derived extracellular matrix proteins like fibronectin which help in joint healing may promote bacterial adhesion and infection. Staphylococcus aureus, Streptococcus spp and Neisseria gonorrhea have a high selectivity for the synovium, probably as a result of adherence characteristics and toxin elaboration. The major determinants of establishing infection are the virulence and tropism of microorganisms combined with the resistance or susceptibility of the synovium.

An increasing body of evidence supports the importance of staphylococcal surface components as virulence determinants by mediating initial colonization. These receptors, termed microbial surface components recognizing adhesive matrix molecules (MSCRAMMs) adhere to host proteins in the joint extracellular matrix, and to implanted medical devices. Some of the host matrix proteins include fibronectin, laminin, elastin, collagen and hyaluronic acid. A number of studies show that mutations in bacterial surface receptors strongly reduce the ability of staphylococci to produce infection [12-15]. However, the role of collagen adhesion of staph aureus as a major virulence factor has been questioned since $30-60 \%$ of clinical isolates display neither collagen binding in vitro or the cna-encoded collagen adhesion [16]. Sequel to adherence, bacteria are internalized by host mechanisms involving membrane pseudopod formation or receptor-mediated endocytosis. These occur through the actions of host cytoskeletal rearrangements via microfilament activity. Once internalized, staphylococci may induce apotosis via a host capase-dependent mechanism or survive intracellularly [17-20]. Induced apoptosis exacerbates the host cell damage in septic arthritis. Staphylococci may utilize invasion as an immunoavoidance technique and escape clearance by the immune system and antimicrobial therapy by persisting in host cells $[9$, 21,22].

The host immune response following colonization and proliferation of bacteria is an acute inflammatory response with elaboration of cytokines [interleukin 1- $\beta$ (IL$1 \beta)$ and interleukin-6(1L-6)] into the joint fluid by synovial cells. These cytokines activate the release of acute phase proteins like c-reative protein from the liver which promote opsonization and complement activation. Bacterial phagocytosis by macrophages, synoviocytes and polymorphonuclear cells leads to the release of tumour alpha necrosis factor, interleukin-8 and granulocyte macrophage colony-stimulating factor. Nitric oxide is also required and $1 \mathrm{~L}-1 \beta$ and $1 \mathrm{~L}-6$ levels increase. T-cell mediated and humoral immune responses also play a role in bacterial clearance or pathogenesis of septic arthritis. When the host response fails to contain the infection quickly, the potent activation of the immune response leads to joint destruction mediated by high levels of cytokines and reactive oxygen species. Host matrix metalloproteinases, lysosomal enzymes and bacterial toxins damage the joint structures. Bacterial toxins include alpha-hemolysin, leukocyte-specific gamma toxin, Staph aureus leukocidin, bacterial superantigens and enterotoxins. Capsular polysaccharide also interferes with opsonization and phagocytosis [9].

The clinical manifestations of septic arthritis include fever and malaise, as well as pain, swelling, warmth and decreased range of movement in the involved joint. A detailed history is useful with attention to risk factors such as extremes of age, degenerative joint disease, rhe- 
umatoid arthritis, and corticosteroid therapy. Diabetes mellitus, intravenous drug abuse, immunosuppressive conditions like HIV, surgeries, renal disease, leukaemia and sepsis/infections in other sites are other risk factors. The Kocher diagnostic criteria for the paediatric septic hip is based on 4 parameters which help differentiate septic arthritis from transient synovitis in children. These are non-weight-bearing on affected side, erythrocyte sedimentation rate (ESR) greater than $40 \mathrm{~mm} / \mathrm{hr}$, fever > $38.5^{\circ} \mathrm{C}$ and a White Blood Cell (WBC) count greater than $12,000 / \mathrm{mm}^{3}$. The probability that the patient has septic arthritis is $99 \%$ when all 4 criteria are met, $93 \%$ when 3 criteria are present, $40 \%$ when 2 criteria are met and $3 \%$ when only one criteria is met. If none is met, the probability of septic arthritis is less than $0.2 \%$ [23-25]. To improve diagnostic accuracy, other researchers have added to Kocher's criteria a c-reactive protein $>200$ $\mathrm{mg} / \mathrm{l}$ or a history of a previous healthcare visit $[26,27]$. Ultimately, the diagnosis of septic arthritis is dependent on isolation of organism(s) from aspirated joint fluid.

Acute septic arthritis is a medical emergency with potential for significant morbidity and mortality. Prompt recognition coupled with rapid and appropriate treatments are pre-requisites for a good prognosis [28]. The treatment options include appropriate antimicrobial therapy and joint drainage. The initial antibiotic therapy is based on Gram Stain, joint fluid analysis, a good history and the mode of presentation. Generally, initial antimicrobials should be broad spectrum and are adjusted, if required based on the culture and sensitivity results. Few controlled studies assess the optimal duration, dose or route of administration of antibiotics [29]. Generally however, most antibiotics achieve excellent concentrations in joint fluid following the parenteral or oral routes, and the usual duration of therapy is 2 weeks for Haemophillus influenza and Streptococcal infections and 3 weeks for infections due to Staphylococcus aureus or the Gramnegative bacilli. The choice of antibiotic therapy in the elderly must be carefully made. These individuals have decreased organ reserve capacity, altered hepatic and renal capacity to handle medications, polypharmacy with associated drug-drug and drug-disease interactions [9]. Antibiotic loading and maintenance doses are estimated by measuring serum peak and trough concentrations after the $4^{\text {th }}$ dose in the elderly.

Infection is a function of the interplay of such factors as host resistance, bacterial dose and virulence. In the developing world with the attendant malnutrition, more children are prone to infections [3]. A high index of suspicion is therefore required and it is important that clinicians bear the possibility in mind when evaluating the irritable or lethargic child. Ultrasonography is non-invasive and is becoming relatively common in urban and sub-urban areas of the developing world. In settings where this investigation is unavailable, arthrocentesis is simple to perform and the fluid sample can be easily assessed for colour, consistency, volume and Gram stain. These should make early diagnosis and appropriate therapy possible. In addition to early antibiotic display, the surgical options for treatment of septic arthritis include needle aspiration, tidal irrigation, arthroscopy and arthrotomy. These can be graded based on invasiveness, cost and effectiveness in the thoroughness of drainage [9]. The need for judicious intervention in this condition has to be understood by physicians especially in our setting where patients are easily lost to follow up and long term outcomes following sub-optimal interventions are difficult to document. Recurrent needle aspirations combined with antibiotics have been used to treat septic arthritis [9]. However, permanent joint damage is established after 5 days of infection $[9,25]$ and there is insufficient evidence to recommend repeated aspirations as routine practice [25]. Tidal irrigation is as effective as Arthroscopy and may be useful when multiple joint aspiration yields fluid with different characteristics, an indication of loculation of pus in different pockets within the joint. Arthroscopic lavage has the advantage of offering extensive debridement with a small incision and is useful in deep joints like the hip. When less invasive options are unavailable or fail, when the patient presents after $3-4$ days, in the presence of osteomyelitis, when the infective organism thrives in low oxygen tensions and require aminoglycosides for treatment, open arthrotomy is indicated [9]. Other indications are the need for urgent decompression because of neuropathy and compromised vascularization, pre-existing joint damage and when the affected joints are inaccessible by less invasive means. Open arthrotomy in all cases of hip and most cases of knee and shoulder sepsis remains a major therapeutic option among Orthopaedic surgeons [25].

This study will document the features and factors that can influence outcomes in this condition in the Cross River Basin area of South-South Nigeria. It will also document the eventual treatment offered patients even when they presented in the hospital first.

\section{Patients \& Methods}

A retrospective analysis of forty-three (43) patients who presented to the University of Calabar Teaching Hospital, Nigeria, with septic arthritis in 45 joints between September, 2007 and August, 2010. Patients' case folders, radiological and microbiological laboratory records were retrieved and information obtained included age, sex, symptoms and duration before presentation, initial health facility used by the patient, and co-morbid factors. 
Other information retrieved included place of abode of the patients, which health professional saw first, final treatment option, microbiological flora as well as the use of imaging studies in the diagnosis. Information obtained was analysed using SPSS version 16. Frequency tables and simple proportions were generated. This retrospective analysis was approved by the Ethics committee.

\section{Inclusion Criteria}

Patients who presented with joint pain, swelling, fever, non weight bearing or refusal to allow joint movement, and whose joint aspirates yielded cloudy or purulent material were included in this analysis. Those patients with the above clinical features but whose joint aspirate yield clear fluid or frank blood were excluded.

\section{Results}

There were forty-five (45) joints with septic arthritis in forty-three (43) patients during the period under review. There were 40 children (aged below 18 years) and 3 adults. Among the children, 24 (60\%) were males and 16 (40\%) were females giving a male: Female ratio of 1.5:1. All the adults in this series were females. The median age of the children was 22.5 months (interquartile range 22.5 months). Thirty-one (31) children (77.5\%) and two (2) adults $(66.6 \%)$ were urban-dwellers respectively, seven children (17.5\%) and one adult (33.3\%) were semi-urban dwellers and two children (5\%) were from rural communities (Table 1). Trauma, sickle cell anaemia and sepsis were significant co-morbid factors accounting for $15 \%$ each for trauma and sickle cell anaemia, and $12.5 \%$ for sepsis in children (Table 2). Fever, joint swelling, pain and non-weight bearing on the affected limb were the presenting clinical features with a median duration of 7 days in both age groups (Figure 1). The knee was the most commonly affected joint in children $(60 \%)$ and adults $(66.7 \%)$ with the left knee predominating in both age groups $(37.5 \%$, children and $66.7 \%$, adults) (Figure 2). In terms of health seeking behavior, 22 children and one adult $(62.5 \%$ and $33.3 \%$ respectively presented first to a hospital, 7 children (17.5\%) and 2 adults (66.7\%) tried self medication or a spiritual healer first before seeking hospital care and 3 children each (7.5\% each) were first seen by either a Pharmacist or a traditional bone setter (Table 3). Twenty-five children $(62.5 \%)$ were first seen by a Paediatrician, $3(7.5 \%)$ by an Orthopaedic surgeon and 4 $(10 \%)$ by a General duty doctor. Two of the adults were first seen by an Orthopaedic surgeon. The definitive treatment options were antibiotics alone in 28 children (70\%) and arthrotomy and washout in 12 children (30\%). All adults had arthrotomy and washout probably because they were all eventually seen by an Orthopaedic surgeon (Table 4). Nineteen (19) patients (44.2\%) did not have a microbiological and sensitivity assay done owing to a

Table 1. Demographic characteristics of patients.

\begin{tabular}{|c|c|c|c|}
\hline Characteristics & $\begin{array}{c}\text { Children (n = 40) } \\
\text { N (\%) }\end{array}$ & Adults $(\mathrm{n}=3)$ & N (\%) \\
\hline Age group (months) & & Age (years) & \\
\hline$<12$ & $12(30.0)$ & & \\
\hline $12-24$ & $10(25.0)$ & $\leq 35$ & $1(33.3)$ \\
\hline $25-36$ & $2(5.0)$ & $>35$ & $2(66.7)$ \\
\hline $37-48$ & $3(7.5)$ & & \\
\hline $49-60$ & $1(2.5)$ & & \\
\hline$>60$ & $12(30.0)$ & & \\
\hline Total & $40(100)$ & & $3(100)$ \\
\hline Sex & & Sex & \\
\hline Male & $24(60.0)$ & Male & $0(0)$ \\
\hline Female & $16(40.0)$ & Female & $3(100)$ \\
\hline Total & $40(100)$ & & $3(100)$ \\
\hline Habitation & & Habitation & \\
\hline Urban & $31(77.5)$ & Urban & $2(66.7)$ \\
\hline Semi-urban & $7(17.5)$ & Semi-urban & $1(33.3)$ \\
\hline Rural & $2(5.0)$ & Rural & - \\
\hline Total & $40(100)$ & & $3(100)$ \\
\hline
\end{tabular}

The median age of children $=22.5$ months $($ Interquartile range $=87$ ). 
Table 2. Co-morbid factors.

\begin{tabular}{lcc}
\hline Co-morbid factors & Children $(\mathrm{n}=40)$ & Adults $(\mathrm{n}=3)$ \\
$\mathrm{n}(\%)$
\end{tabular}

Table 3. Health seeking behaviour.

\begin{tabular}{lcc}
\hline & $\begin{array}{c}\text { Children }(\mathbf{n}=\mathbf{4 0}) \\
\mathbf{N}(\mathbf{\%})\end{array}$ & $\begin{array}{c}\text { Adults }(\mathbf{n}=3) \\
\mathbf{N}(\%)\end{array}$ \\
\hline First health seeking behavior & & $1(33.3)$ \\
Hospital & $22(62.5)$ & $2(66.7)$ \\
Self medication/spiritual healer & $7(17.5)$ & $0(0)$ \\
Chemist & $5(12.5)$ & $0(0)$ \\
Pharmacy & $3(7.5)$ & $0(0)$ \\
Traditional Bonesetter & $3(7.5)$ & $\mathbf{3 ( 1 0 0 )}$ \\
Total & $\mathbf{4 0 ( 1 0 0 )}$ & \\
\hline
\end{tabular}

Table 4. Treatment Intervention.

\section{Children $(n=40)$}

n (\%)

Medical doctor who saw first

Paediatrician

Orthopaedic surgeon

General duty doctor

Others*

Total

Definitive treatment option

Conservative (Antibiotics alone)

Arthrotomy and washout

Total
25(62.5)

$3(7.5)$

$4(10.0)$

$8(20.0)$

40(100.0)
Adults (n = 3) n (\%)

"Others: Patent medicine vendors, Traditional bone setters, Spiritual healers.

3(100.0) 


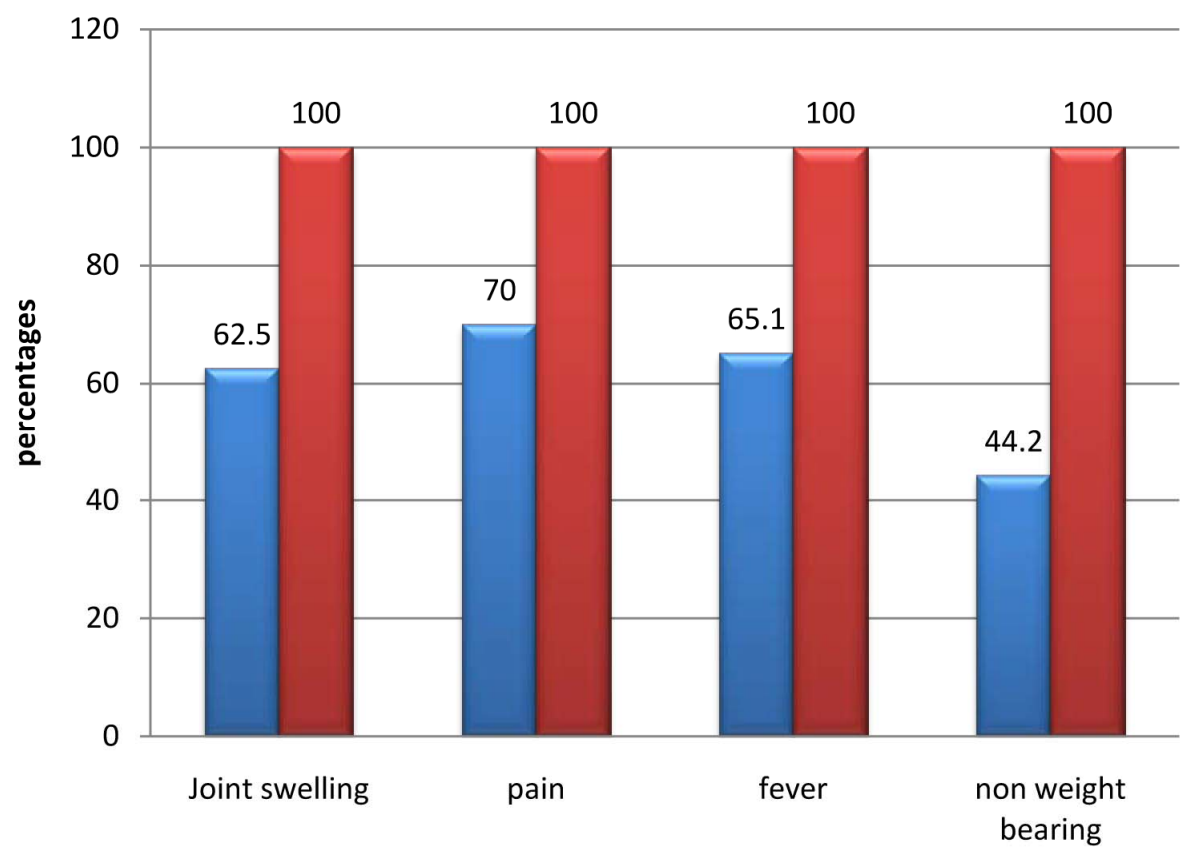

Children

Adults

Median duration of joint swelling $=7$ days $($ IQ range $=10$ ); Median duration of fever $=7$ days $($ IQ range $=8$ ); Median duration of pain $=7$ days $($ IQ range $=11)$; Median duration of loss of function $=7$ days $($ IQ range $=11)$.

Figure 1. Clinical symptoms.

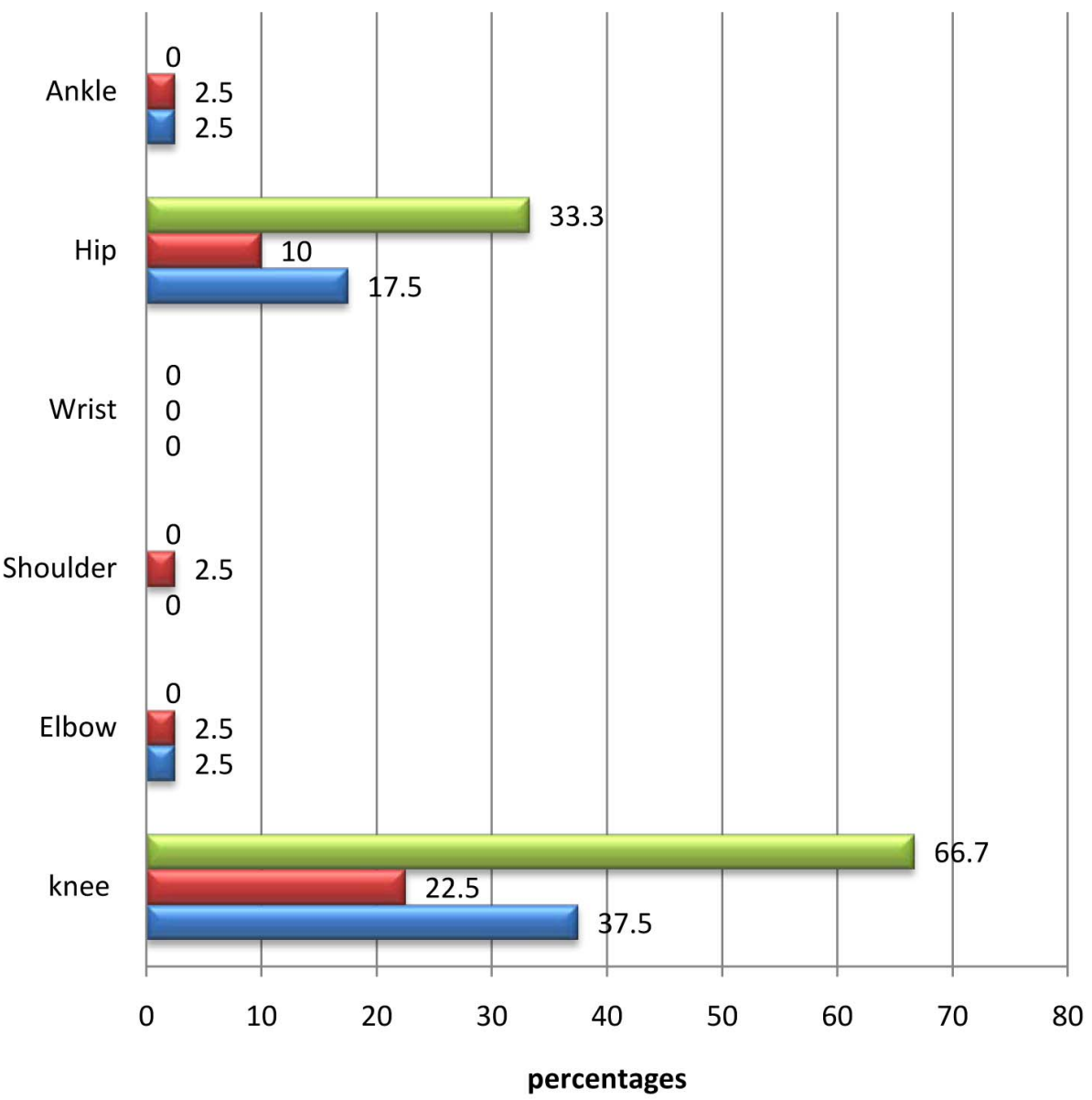

$\square$ left(adult)

right(child)

left(Child)

Figure 2. Sites of involvement. 
variety of factors including poverty and faulty equipment. Among those who had a microbiological and sensitivity assay performed, Staphylococcus aureus was the most common pathogen (25\%), followed by Enterobacteriacae and Pseudomonas auroginosa (5\% each). Four specimens $(10 \%)$ grew no isolates.

\section{Discussion}

Pyogenic arthritis is an emergency where prompt diagnosis, rapid and aggressive antimicrobial therapy, arthrotomy and washout are critical to ensuring good prognosis $[1,9]$. Whereas the pathogenesis is multifactorrial and diagnosis based on isolation of bacterial species from synovial fluid, there is a major role for clinical history, physical signs of inflammation, infection, laboratory features, and imaging studies [9]. The condition is managed in conjunction with an Orthopaedic surgeon [25].

The findings in this study agree with other studies that Staphylococcus aureus is the commonest causative organism $[1,10,30,31]$, and the knee joint is the commonest affected joint $[1,10,12]$. Our findings also agree with other reports from Nigeria which identified trauma and sickle cell disease as significant co-morbid factors and a male preponderance $[1,4,5]$, but differs from a SouthWestern Nigerian study which identified the upper limb joints as being the most commonly affected joints in children below the age of one year [1]. In our study, the knee joint remained the commonest affected joint in this age group (11 cases, $27.5 \%$ ). Traditional massage practices may account for this difference.

The South-Western Nigerian study reported that inadequate antibiotic therapy occurred in $64.1 \%$ of their patients and concluded that patient education on early presentation, avoidance of improper use of antibiotics and regular follow up after acute pathology should be encouraged ${ }^{1}$. In our study, twenty-five children $(62.5 \%)$ saw a Paediatrician first but only $12(30 \%)$ out of 40 children had arthrotomy and washout combined with antibiotics. Education on the avoidance of improper antibiotic use may therefore need to be directed at patients and physicians as well. Considering the near absent tradition of follow-up in our setting $[1,4,8]$, it will be difficult to assess the degree of disability that may attend a significant proportion of those patients who had conservative treatment without joint lavage. Antibiotic treatment alone is insufficient for established septic arthritis [32].

Studies from Africa commonly identify late presentation and injudicious health-seeking behavior as underlying factors in inappropriate treatment and potential poor outcomes $[1,3,8,26,28]$. This study however shows that a total of 23 patients $(53.5 \%)$ sought healthcare in a hospi- tal first. However, only 12 children and all 3 adults saw an orthopaedic surgeon either at their first visit or subsequently. Among those who were eventually referred to the orthopaedic surgeons the average interval between when the patients were seen by a paediatrician or general duty doctor and when they were referred was 4 days $(96$ hours). This may strengthen the argument that healthcare outcomes in Africa are a factor of the skewed distribution of the healthcare workforce and weak referral systems which may be significant determinants of poor outcomes in musculoskeletal disease in Africa [3].

Permanent destruction of intra-articular cartilage and sub-chondral bone loss begins within 24 hours and can be established by 3 days in septic arthritis [9,33]. A South African study has shown that patients with septic arthritis who had arthrotomy within 5 days of onset of symptoms had good long term prognosis while those who had arthrotomy after 5 days had poor long term prognosis $[25,28]$. Articular destruction results from a combination of high levels of cytokines, reactive oxygen species, release of lysosomal enzymes and bacterial toxins [33]. The early occurrence of cartilage and joint damage underscores the need for early and judicious intervention to reduce microbial load by joint lavage and reduce the potential risk for articular destruction. In this report, $30 \%$ of children had arthrotomy and joint lavage despite $62.5 \%$ seeking hospital care as the first healthseeking behavior. The remaining children received only antibiotics and were discharged. Although all the patients who had arthrotomy and joint washout combined with antibiotics in this study had a satisfactory outcome 12 weeks post operatively, a previous Nigerian study had reported poor outcomes in $47.1 \%$ of patients with septic arthritis of the hip [34]. Lack of adequate follow-up in our setting inhibits an objective evaluation of long-term outcomes, especially in the $70 \%$ of children who only received antibiotics without joint lavage. The combination of skewed healthcare workforce distributions, late presentation (median duration of symptoms of 7 days in this study) and a poor culture of follow-up strengthen the argument for judicious and often "radical" interventions in musculoskeletal septic diseases at first contact in the developing world $[3,7,35]$. This, and the strengthening of the referral chain must be the take home lesson for physicians working in these regions.A simple set of standard operating protocols that insist that all patients with septic arthritis must benefit from Orthopaedic review is an essential first step in these settings.

\section{Conclusion}

This study shows that despite a significant number of patients with septic arthritis presenting first to a hospital, the median duration of symptoms was prolonged and 
only a small proportion presented to an Orthopaedic surgeon. While patient education remains crucial, physicians also need to be targeted to address the issues of judicious interventions and strengthening of the referral chain. Continuing medical education must seek to draw attention to the issues of intra-professional communication and practices that promote poor outcomes in the developing world. This is especially critical in those regions where the patient's attitude to long term follow-up is poor. Simple practices like standard operating protocols that insist on minimum standards of care and referrals can have a dramatic impact on long term outcomes in this condition.

\section{REFERENCES}

[1] J. D. Ogunlusi, O. O. Ogunlusi, L. M. Oginni and J. A. Olowookere, "Septic Arthritis in a Nigerian Tertiary Hospital," Iowa Orthopaedic Journal, Vol. 26, 2006, pp. 45-47.

[2] I. A. Ikpeme, A. M. Udosen and I. Okereke-Okpa, "Patients' Perception of Traditional Bone Setting in Calabar," Port Harcourt Medical Journal, Vol. 1, No. 2, 2007, pp. 104-108.

[3] M. Segbefia and A. Howard, "Acute Septic Arthritis and Osteomyelitis in Children-An African Perspective," 2013. http://ptolemy.library.utoronto.ca/sites/default/files/review/201 0/February-Acuteseptic Arthritis and Osteomyelitis.pdf

[4] G. O. Eyichukwu, "Outcome of Management of NonGonococcal Septic Arthritis at National Orthopaedic Hospital, Enugu, Nigeria," Nigerian Medical Journal, Vol. 19, No. 1, 2010, pp. 69-76.

[5] A. L. Akinyoola, P. O. Obiajunwa, L. M. Oginni, "Septic Arthritis in Children," West African Journal of Medicine, Vol. 25, No. 2, 2006, pp. 119-123.

[6] G. O. Onyemelukwe and R. D. Sturrock, "Septic Arthritis in Northern Nigeria," Rheumatology, Vol. 18, No. 1, 1979, pp. 13-17.

[7] M. Mijiyawa, O. Oniankitan, K. Attoh-Mensah, A. Tékou, E. K. Lawson, G. B. Priuli and J. K. Assimadi, "Musculoskeletal Conditions in Children Attending Two Togolese Hospitals," Rheumatology, Vol. 38 No. 10, 1999, pp. 1010-1013. doi:10.1093/rheumatology/38.10.1010

[8] N. Eke, "Late Presentation Begs for a Solution," Port Harcourt Medical Journal, Vol. 1, No. 2, 2007, p. 75.

[9] M. E. Shirtlift and J. T. Mader, "Acute Septic Arthritis," Clinical Microbiology Reviews, Vol. 15, No. 4, 2002, pp. 527-544.

[10] D. S. Morgan, D. Fisher, A. Merianos and B. J. Currie, "An 18-Year Clinical Review of Septic Arthritis from Tropical Australia," Epidemiology \& Infection, Vol. 117, No. 3, 1996, pp. 423-428. doi: $10.1017 / \mathrm{S} 0950268800059070$

[11] L. Le Dantec, F. Maury, R. M. Flipo, S. Laskri, B. Corlet, B. Duquesnoy and B. Delcambre, "Peripheral Septic Ar- thritis. A Study of One Hundred and Seventy-Nine Cases," Revue du rhumatisme (English Edition), Vol. 63, No. 2, 1996, pp. 103-110.

[12] I. M. Nilsson, J. M. Patti, T. Bremell, M. Hook and A. Tarwoski, "Vaccination with a Recombinant Fragment of Collagen Adhesin Provides Protection against Staphylococcus Aureus Mediated Septic Death," Journal of Clinical Investigation, Vol. 101, No. 12, 1998, pp. 2640-2649. doi:10.1172/JCI1823

[13] A. H. Patel, P. Nowlan, E. D. Weavers and T. Foster, "Virulence of Protein A-Deficient and alpha-Toxin-Deficient Mutants of Staphylococcus aureus Isolated by Allele Replacement," Infection and Immunity, Vol. 5, No. 12, 1987, pp. 3103-3110.

[14] S. J. Peacock, N. P. Day, M. G. Thomas, A. R. Berendt and T. J. Foster, "Clinical Isolates of Staphylococcus aureus Exhibit Diversity in Fnb Genes and Adhesion to Human Fibronectin," Journal of Infection, Vol. 41, No. 1, 2000, pp. 23-31. doi:10.1053/jinf.2000.0657

[15] L. M. Switalski, J. M. Patti, W. Butcher, A. G. Gristina, P. Speziale and M. Hook, "A Collagen Receptor on Staphylococcus aureus Strains Isolated from Patients with Septic Arthritis Mediates Adhesion to Cartilage," Molecular Microbiology, Vol. 7, No. 1, 1993. pp. 99-107. doi:10.1111/j.1365-2958.1993.tb01101.x

[16] M. G. Thomas, S. Peacock, S. Daenke and A. R. Berendt, "Adhesion of Staphylococcus aureus to Collagen Is Not a Major Virulence Determinant for Septic Arthritis, Osteomyelitis or Endocarditis," The Journal of Infectious Diseases, Vol. 179, No. 1, 1999, pp. 291-293. doi: $10.1086 / 314576$

[17] J. K. Ellington, S. S. Reilly, W. K. Ramp, M. S. Smeltzer, J. F. Kellam and M. C. Hudson, "Mechanisms of Staphylococcus aureus Invasion of Cultured Osteoblasts," Microbial Pathogenesis, Vol. 26, No. 6, 1999, pp. 317-323. doi:10.1006/mpat.1999.0272

[18] A. Lammers, P. J. Nuÿten and H. E. Smith, "The Fibronectin Binding Properties of Staphylococcus aureus Are Required for Adhesion to and Invasion of Bovine Mammary Gland Cells," FEMS Microbiology Letters, Vol. 180, No. 1, 1999, pp. 103-109. doi:10.1111/j.1574-6968.1999.tb08783.x

[19] B. E. Menzies and I. Kourteva, "Internalization of Staphylococcus aureus by Endothial Cells Induces Apoptosis," Infection and Immunity, Vol. 66, No. 12, 1998, pp. 5994-1998.

[20] C. A. Wesson, J. Deringer, L. E. Liou, K. W. Bayles, G. A. Bohach and W. R. Trumble, "Apoptosis Induced by Staphylococcus aureus in Epithelial Cells Utilizes a Mechanism Involving Caspases 8 and 3," Infection and Immunity, Vol. 68, No. 5, 2000, pp. 2998-3001. doi:10.1128/IAI.68.5.2998-3001.2000

[21] S. S. Reilly, M. C. Hudson, J. F. Kellam and W. K. Ramp, "In Vivo Internalization of Staphylococcus aureus by Embryonic Chick Osteoblasts," Bone, Vol. 26, No. 1, 2000, pp. 63-70. doi:10.1016/S8756-3282(99)00239-2

[22] H. D. Gresham, J. H. Lowrance, T. E. Caver, B. S. Wilson, A. L. Cleung and F. P. Lindberg, "Survival of Sta- 
phylococcus aureus inside Neutrophils Contributes to Infection," The Journal of Immunology, Vol. 164, No. 7, 2000, pp. 3713-3722.

[23] M. S. Kocher, D. Zurakowski and J. R. KAsser, "Differentiating between Septic Arthritis and Transient Synovitis of the Hip in Children; an Evidence-Based Clinical Prediction Algorithm," The Journal of Bone \& Joint Surgery, Vol. 81, No. 12, 1999, pp. 1662-1670.

[24] M. S. Kocher, R. Mandiga, D. Zurakowski, C. Barnwoh and J. R. Kasser, "Validation of a Clinical Prediction Rule for the Differentation between Septic Arthritis and Transient Synovitis of the Hip in Children," The Journal of Bone \& Joint Surgery, Vol. 86, No. 8, 2004, pp. 16291635.

[25] A. Howard and M. Wilson, "Easily Missed? Septic Arthritis in Children," BMJ, Vol. 341, 2010, Article ID: c4407. doi:10.1136/bmj.c4407

[26] S. J. Luhmann, A. Jones, M. Schootman, J. E. Gordon, P. L. Schoeneker and J. D. Luhmann, "Differentiation between Septic Arthritis and Transient Synovitis of the Hip in Children with Clinical Prediction Algorithms," The Journal of Bone \& Joint Surgery, Vol. 86, No. 5, 2004, pp. 956-962.

[27] M. S. Caird, J. M. Flynn, Y. L. Leung, J. E. Millman, J. G. D'Italia and J. P. Dormans, "Factors Distinguishing Septic Arthritis from Transient Synovitis of the Hip in Children. A Prospective Study," The Journal of Bone \& Joint Surgery, Vol. 88, No. 6, 2006, pp. 1251-1257. doi:10.2106/JBJS.E.00216

[28] T. R. Nunn, W. Y. Cheung and P. D. Rollinson, "A ProSpective Study of Pyogenic Sepsis of the Hip in Childhood," The Journal of Bone \& Joint Surgery, Vol. 89, No.
1, 2007, pp. 100-106. doi:10.1302/0301-620X.89B1.17940

[29] J. Black, T. L. Hunt, P. J. Godley and E. Mathew, "Oral Antimicrobial Therapy for Adults with Osteomyelitis or Septic Arthritis," The Journal of Infectious Diseases, Vol. 155, No. 5, 1987, pp. 968-972. doi:10.1093/infdis/155.5.968

[30] M. Razak and J. Nasiruddin, "An Epidemiological Study of Septic Arthritis in Kuala Lumpur Hospital," Medical Journal of Malaysia, Vol. 53, Suppl. A, 1998, pp. 86-94.

[31] A. K. Shetty and A. Gedalia, "Management of Septic Arthritis," Indian Journal of Pediatrics, Vol. 71, No. 9, 2004, pp. 819-824. doi:10.1007/BF02730722

[32] P. Riegels-Nielsen, N. Frimodt-Moller, M. Sorensen and J. S. Jensen, "Antibiotic Treatment Insufficient for Established Septic Arthritis. Staphylococcus aureus Experiments in Rabbits," Acta Orthopaedica Scandinavica, Vol. 60, No. 1, 1989, pp. 113-115. doi:10.3109/17453678909150107

[33] S. Roy and J. Bhawan, "Ultrastructure of Articular Cartilage in Pyogenic Arthritis," Archives of Pathology, Vol. 99, No. 1, 1975, pp. 44-47.

[34] A. L. Akinyola, P. O. Obiajunwa, L. M. Oginni and S. I. I. Adeoye, "Septic Arthritis of the Hip in Nigerian Children," African Journal of Paediatric Surgery, Vol. 1, No. 2, 2005, pp. 56-61.

[35] I. A. Ikpeme, A. M. Udosen, A. A. Ikpeme, G. U. Inah and Q. N. Kalu, "Early Outcome of Treatment of Chronic Osteomyelitis Using the Improvised Irrigation and Drainage System for the Lautenbach Procedure," International Journal of Tropical Surgery, Vol. 3, No. 3, 2009, pp. 110115. 